\title{
DERECHO Y POLÍTICAS AMBIENTALES EN CANTABRIA (SEGUNDO SEMESTRE 2017)
}

\author{
Marcos Gómez Puente \\ Catedrático de Derecho Administrativo \\ Universidad de Cantabria
}


Sumario: 1. La actividad de fomento en materia ambiental. 2. El Plan de Ordenación de los Recursos Naturales de las Dunas de Liencres, Estuario del Pas y Costa Quebrada.

\section{LA ACTIVIDAD DE FOMENTO EN MATERIA AMBIENTAL}

Después de haber dado cuenta en la primera crónica del año del contenido ambiental de la Ley de Presupuestos de la Comunidad, de la significación económica de la política ambiental, a través de las inversiones previstas, parece oportuno ahora esbozar cuál es el destino del gasto en subvenciones y otras ayudas de finalidad ambiental, que puede rastrearse siguiendo las distintas convocatorias de ayudas que han jalonado el diario oficial a lo largo de 2017.

Realizadas desde la Consejería de Universidades e Investigación, Medio Ambiente y Política Social (UMA) o desde la Consejería de Medio Rural, Pesca y Alimentación (MED), los destinatarios de estas convocatorias son, sobre todo, los Municipios y Entidades Locales de la Región, aunque algunas también han ido dirigidas a entidades corporativas, asociaciones y particulares.

Entre las primeras pueden enumerarse las siguientes:

- Ayudas para la limpieza de playas rurales (Orden UMA/13/2017, de 24 de marzo).

- Ayudas para financiar actuaciones de los Ayuntamientos en el procedimiento de elaboración de Bases de Datos de Áreas Degradadas -BDADs- (Orden UMA/19/2017, de 19 de abril), que forman parte de la "Estrategia de Recuperación de Áreas Degradadas, ERAD2020" definida por la Administración regional, para la que se cuenta con la colaboración de la Federación de Municipios de Cantabria. Sus objetivos responden a tres líneas de actuación: la restauración o reposición ambiental o ecológica de los espacios degradados; su reutilización en condiciones mejoradas, y la identificación de nuevos usos y valores subsecuentes a la rehabilitación que propicien su mantenimiento.

- Ayudas para inversiones y proyectos para la ejecución de medidas orientadas a cumplir los objetivos de la Estrategia (regional) de Acción 
frente al Cambio Climático (Orden UMA/24/2017, de 24 de mayo). Esta estrategia fue aprobada en 2008 para el horizonte 2008-2012 e incluyó una serie de medidas para la mitigación de emisiones y adaptación a los efectos del cambio climático. Obviamente, desde su aprobación se han producido sustanciales novedades tanto en el marco internacional (la más relevante, el Acuerdo Universal sobre el Cambio Climático surgido de la Conferencia de París, que refiere un compromiso vinculante para la reducción de emisiones contaminantes a la atmósfera a partir del año 2020, con el objetivo principal limitar el aumento de la temperatura global en menos de $2^{\circ} \mathrm{C}$ ) y europeo (piénsese en la evolución del régimen de comercio de derechos de emisión de gases de efecto invernadero y en el Paquete Europeo de Energía y Cambio Climático 2013-2020, que contempla novedades como la captura y almacenamiento de carbono, y la Hoja de Ruta hacia una economía competitiva baja en carbono en 2050) que han sido incorporadas a la Estrategia Española de Cambio Climático y Energía Limpia 2007-2012-2020 y a la Hoja de Ruta de los Sectores Difusos a 2020, con el propósito de impulsar y facilitar la transición hacia una economía de baja emisión de carbono de una forma eficiente. Un nuevo escenario de objetivos ante el que el Gobierno regional considera necesario elaborar una nueva estrategia de lucha frente al cambio climático sin perjuicio de seguir desarrollando, entretanto, prácticas y políticas de mitigación y adaptación al cambio climático. $Y$ entre éstas, las dirigidas a involucrar las entidades locales en esta lucha, finalidad con las que se les ofrecen ayudas para (i) implantar una herramienta de diagnóstico -la determinación de la huella local de carbono-, sensibilizar y formar al personal municipal en esta materia y desarrollar actividades de investigación y difusión; (ii) desarrollar proyectos de absorción de $\mathrm{CO}_{2}$; (iii) actuaciones relacionadas con la movilidad que contribuyan a reducir las emisiones de gases de efecto invernadero derivadas de ella -piénsese, por ejemplo, en la modernización del parque de autobuses urbanos-; y (iv) mejorar el ahorro y la eficiencia energética en las dependencias municipales e implantar energías renovables. 
- Ayudas para instalaciones de energías renovables y de ahorro y eficiencia energética en los servicios públicos municipales (Orden MED/25/2017, de 20 de junio). Con la misma vocación que las ayudas anteriores, en este caso se parte de la existencia de instalaciones (depuradoras, depósitos de agua, estaciones de bombeo, repetidores de comunicaciones, refugios de pastoreo, etc.) aisladas y sin conexión a la red eléctrica, alimentadas por sistemas autógenos de combustión o infrautilizadas 0 abandonadas, que se pretenden renovar y recuperar dotándoles de un sistema autónomo de suministros sustentando en energías renovables (solar, eólica, hidráulica), con el fin de ponerlas nuevamente en servicio para el uso y disfrute de los vecinos sin coste ambiental.

- Ayudas para la creación de instrumentos de información urbanística (Orden UMA/35/2017, de 23 de junio) y para la redacción de planes urbanísticos y de planes especiales de suelo rústico (Orden UMA/25/2017, de 24 de mayo).

- Ayudas para la realización de obras nuevas y de mejora de las infraestructuras agrarias orientadas por el principio de sostenibilidad ambiental (Orden MED/21/2017, de 12 de junio).

- Ayudas para actuaciones de prevención de incendios forestales (Orden MED/35/2017, de 25 de agosto), siendo oportuno anotar que también en 2017 fueron numerosos y extensos los incendios acaecidos a lo largo de las estaciones (no solo en verano) y que se ha definido un Plan Estratégico para la Prevención y Lucha contra Incendios, aprobado el 22 de junio de 2017, que contempla una inversión, para el periodo 20172020, de casi $26 \mathrm{M} €$.

- Ayudas para los Grupos de Acción Local del Programa Leader de Cantabria 2014-2020 (Orden MED/44/2017, de 14 de noviembre), destinadas a promover la existencia de servicios básicos en las zonas rurales y la renovación de sus poblaciones. De conformidad con lo previsto en el Reglamento UE/1305/2013, con estas ayudas puede financiarse (i) la elaboración y actualización de planes para el desarrollo 
de los municipios y las poblaciones de las zonas rurales y sus servicios básicos, y de planes de protección y gestión correspondientes a zonas de la red Natura 2000 y otras zonas de alto valor natural; (ii) las inversiones para la creación, mejora o ampliación de todo tipo de pequeñas infraestructuras, entre ellas las inversiones en energías renovables y en el ahorro energético; (iii) los estudios e inversiones vinculados al mantenimiento, la recuperación y la rehabilitación del patrimonio cultural y natural de las poblaciones, de los paisajes rurales y de las zonas de alto valor natural, incluidos sus aspectos socioeconómicos, así como las iniciativas de sensibilización ecológica; y (iv) las inversiones que tengan por objeto el traslado de actividades y la transformación de edificios $u$ otras instalaciones situados cerca o dentro de los núcleos de población rural, a fin de mejorar la calidad de vida o los resultados medioambientales de tales núcleos.

$Y$ entre las dirigidas a corporaciones o entidades (sociedades, asociaciones, fundaciones...) privadas y personas físicas están:

- Ayudas a la primera instalación de jóvenes y la modernización de las explotaciones agrarias en Cantabria (Orden MED/5/2017, de 8 de marzo, que modifica la Orden MED/44/2016, de 12-9-2016, por la que se establecen las bases reguladoras de estas ayudas), que se otorgan con criterios de sostenibilidad ambiental e impulso del medio rural y natural.

- Ayudas a inversiones realizadas por Cofradías de Pescadores de Cantabria, cofinanciadas por el Fondo Europeo Marítimo y de la Pesca (2014-2020) (Orden MED/17/2017, de 15 de mayo), que se adjudican también tomando en cuenta su interés ambiental, por ser "el fomento de una pesca sostenible desde el punto de vista medioambiental, eficiente en el uso de recursos, innovadora, competitiva y basada en el conocimiento" una de las prioridades de la Unión Europea (Reglamento UE/508/2014 del Parlamento Europeo y del Consejo de 15 de mayo de 2014 relativo al Fondo Europeo Marítimo y de Pesca -FEMP-, art. 6.1). Así, los objetivos que persiguen estas ayudas son la mejora de la 
eficiencia energética, la protección del medio ambiente y la recogida de residuos y desechos marinos.

- Subvenciones para el desarrollo de proyectos innovadores en relación a la Asociación Europea de Innovación de Agricultura Productiva y Sostenible (Orden MED/33/2017, de 21 de agosto).

- Ayudas con cargo a los fondos FEADER y FEAGA que se supeditan al cumplimiento de buenas condiciones agrarias y medioambientales (Orden MED/37/2017, de 4 de septiembre), de conformidad con lo previsto en el Reglamento UE/1306/2013, del Consejo, de 17 de diciembre, de Financiación, gestión y seguimiento de la Política Agrícola Común, y el Real Decreto 1078/2014, de 19 de diciembre.

- Así, entre las condiciones exigibles para cumplir las buenas condiciones agrarias y medioambientales de la tierra en lo que se refiere a los aspectos principales de agua, suelo y paisaje, resultan de obligado cumplimiento: (i) La creación y conservación de franjas de protección de al menos 5 metros en las márgenes de ríos, lagunas y humedales, en las que no se podrá aplicar fertilizantes ni fitosanitarios; (ii) La preceptiva autorización para el uso de agua de riego, debiendo estar acreditado el derecho correspondiente; (iii) la protección de las aguas subterráneas de la contaminación por sustancias peligrosas (prohibición de vertidos); (iv) la cobertura mínima del suelo de cultivo y de las condiciones de laboreo para evitar la erosión (mantenimiento del nivel de materia orgánica en el suelo mediante prácticas adecuadas, incluida la prohibición de quemar rastrojos salvo por razones fitosanitarias); y (v) el mantenimiento de las particularidades topográficas o elementos del paisaje y prohibición de cortar setos y árboles durante la temporada de cría y reproducción de las aves.

- Además, en una región como la cántabra, con valles en los que predomina la pradería, tiene especial interés la obligación de proteger los pastos, quedando excluida (para el acceso a estas ayudas) la quema de los pastos permanentes o la roturación de pastos declarados 
medioambientalmente sensibles salvo para labores de regeneración de la vegetación.

- Otros aspectos que se tienen en cuenta son (i) el correcto almacenamiento de estiércoles ganaderos para evitar el deterioro de los hábitat, de modo que se eviten riesgos de filtración y contaminación de las aguas superficiales y subterráneas (exigiéndose a las explotaciones ganaderas en estabulación permanente 0 semipermanente que dispongan de tanques de almacenamiento o fosas, estercoleros y balsas impermeabilizadas); (ii) el control del abandono y vertido de materiales residuales procedentes del uso de medios de producción agrícolas y ganaderos (plásticos, envases, embalajes, y restos de maquinaria, aceites y lubricantes así como los residuos de fitosanitarios, zoosanitarios y de productos de uso veterinario), que deben ser clasificados y concentrados en puntos concretos y discretos de la explotación hasta su traslado definitivo a vertederos o plantas de tratamiento autorizado.

- Ayudas para proyectos de fomento de la bicicleta en centros educativos de enseñanza no universitaria -Programa +BICEPS- (Orden UMA 44/2017, de 20 de septiembre, que modifica la Orden UMA/13/2016, de 5-5-2016).

\section{EL PLAN DE ORDENACIÓN DE LOS RECURSOS NATURALES DE LAS DUNAS DE LIENCRES, ESTUARIO DEL PAS Y COSTA QUEBRADA}

Por los municipios de Miengo, Piélagos y Santa Cruz de Bezana (estos dos últimos limítrofes con el de Santander) se extiende un espacio natural conformado por las dunas de Liencres, el estuario del Pas y la denominada Costa Quebrada para el que, tras varias décadas de espera, acaba de aprobarse ahora un PORN (Decreto 60/2017, de 7 de septiembre).

En efecto, el Parque Natural de las Dunas de Liencres fue creado por Decreto 101/1986, de 9 de diciembre, siendo su principal elemento natural el sistema dunar situado en la margen derecha de la desembocadura del río Pas (con escasa extensión, apenas 194,55 hectáreas, sus límites fueron descritos por la 
Ley de Cantabria 4/2006, de 19 de mayo, Anexo III). Y posteriormente, la Comisión Europea incluyó entre los Lugares de Importancia Comunitaria de la región biogeográfica atlántica (Decisión de 7 de diciembre de 2004, adoptada de conformidad con la Directiva 92/43/CEE), el lugar de las «Dunas de Liencres y Estuario de Pas» (que incluía la totalidad del Parque y el estuario del Pas y una franja costera, hasta alcanzar una extensión de 544,21 hectáreas), tratándose de un lugar con elementos geomorfológicos y paisajísticos de gran valor, con una notable geodiversidad (elevaciones litorales, plataformas de abrasión, playas y dunas, acantilados, tómbolos e islotes, que explican su denominación -Costa Quebrada- y justifican su inclusión en el Inventario Nacional de Puntos de Interés Geológico del Instituto Tecnológico Geominero de España) y biodiversidad (matorral -landas costeras-, praderías o comunidades de aves marinas) $y$, parece oportuno añadir, no exento de presión urbanística por la fuerte demanda de vivienda que suscita dicha zona por su belleza, proximidad a las playas e interés turístico.

De ahí que resultara necesaria su ordenación específica y el Gobierno regional pusiera en marcha la tramitación del Plan de Ordenación de los Recursos Naturales de las Dunas de Liencres, Estuario del Pas y Costa Quebrada (Orden GAN/67/2006, de 21 de julio, modificada por la Orden GAN/51/2012, de 8 de agosto), de conformidad con lo previsto en el artículo 59 de la Ley de Cantabria 4/2006, de 19 de mayo, de Conservación de la Naturaleza de Cantabria, aunque hasta abril de 2010 no se inició la pertinente tramitación de la Evaluación de Impacto Ambiental del referido instrumento, cuya Memoria Ambiental fue finalmente aprobada en agosto de 2014.

EI PORN está integrado por los siguientes instrumentos:

- La Memoria de Ordenación, que incluye la descripción e interpretación de las principales características físicas y biológicas del territorio; la definición del estado de conservación de los recursos naturales con formulación de un diagnóstico de los mismos y una previsión de su evolución futura; el análisis del estado socio-económico de la zona y la estimación de los costes de aplicación del Plan. 
- Las Normas de Ordenación que, sobre la base del análisis de los recursos naturales y sus criterios de ordenación expuestos en la Memoria, incorporan la determinación de las limitaciones generales y específicas que, respecto de los usos y actividades, hayan de adoptarse en función de los objetivos de conservación establecidos con especificación de las distintas zonas, así como el establecimiento de los criterios orientadores en la formulación y ejecución de las diversas políticas sectoriales que inciden en el ámbito territorial objeto del Plan que garanticen su mínimo impacto sobre la conservación de los recursos naturales.

- Los Planos de Información, que son la traslación gráfica de los contenidos de la Memoria de Ordenación y de las Normas de Ordenación. 
PLAN DE ORDENACIÓN DE LOS RECURSOS NATURALES DE LAS DUNAS DE LIENCRES, ESTUARIO DEL PAS Y COSTA QUEBRADA

\section{CARTOGRAFIA}
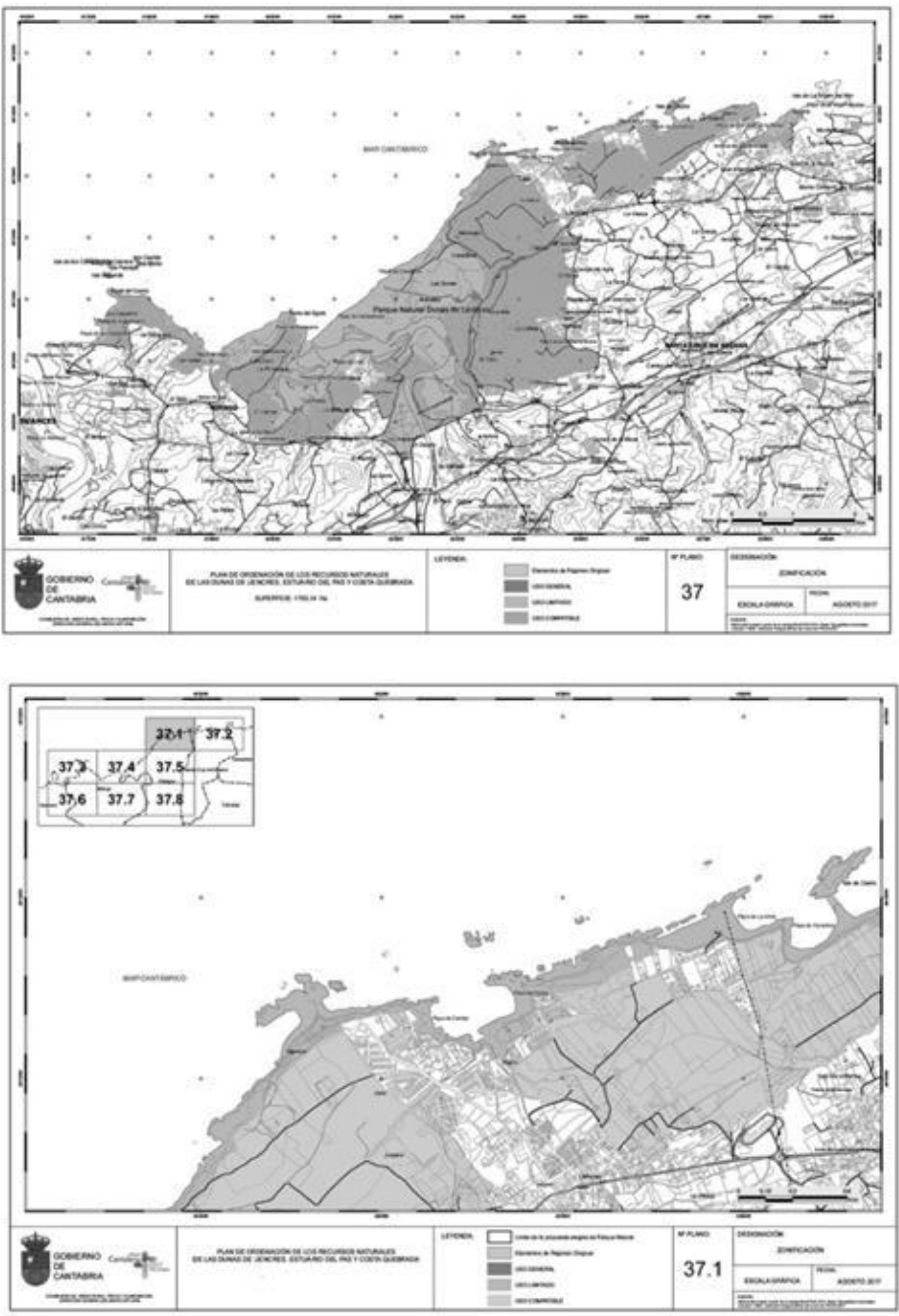